\title{
Formação política para fortalecimento de liderança em enfermagem: um relato sobre a experiência
}

Recebido em: 18/05/2012

Aceito em: 27/09/2012

\author{
Jouhanna do Carmo Menegaz' \\ Vânia Marli Schubert Backes² \\ Simone Coelho Amestoy
}

Relato de experiência sobre o curso de formação política realizado por entidades de classe com o objetivo de destacar a potencialidade da formação política para o fortalecimento da liderança em enfermagem apresentado de forma articulada ao referencial freireano e de Hannah Arendt. O curso estimulou o debate e a socialização entre pares, assim como a reafirmação das lutas e da atuação da categoria no contexto dos serviços de saúde. Concluise que iniciativas como o curso de formação política possam ser disseminadas ultrapassando a ampliação ou atualização de conhecimentos possibilitando a incorporação de argumentos e novas posturas de liderança na enfermagem.

Descritores: Enfermagem; Liderança; Formação de Recursos Humanos.

\section{Political education to strengthen leadership in nursing: an experience report}

Experience report about political training course conducted by professional associations in order to highlight the potential of political education to strengthen nursing leadership presented in an articulate way to frame Freire and Hannah Arendt. The course has stimulated debate and socialization among peers, as well as a reaffirmation of the struggles and the acting category in the context of health services. It is concluded that initiatives such as training course policy could be spread beyond the expansion or upgrading of knowledge enabling the incorporation of new arguments and positions of leadership in nursing.

Descriptors: Nursing; Leadership; Human Resources Formation.

\section{Formación política para fortalecimiento del liderazgo en enfermería: un relato de experiencia}

Relato de experiencia del curso de formación política realizado por las asociaciones profesionales con el fin de poner de relieve el potencial de la educación política para fortalecer el liderazgo de enfermería presentó de manera articulada al marco de Freire y Hannah Arendt. El curso ha estimulado el debate y la socialización entre pares, así como una reafirmación de las luchas y de la actuación de la categoría en el contexto de los servicios de salud. Se concluye que las iniciativas como la política de cursos de formación podrían extenderse más allá de la ampliación o mejora de los conocimientos permitiendo la incorporación de nuevos argumentos y posiciones de liderazgo en la enfermería.

Descriptores: Enfermería; Liderazgo; Formación de Recursos Humanos.

\section{INTRODUÇÃO}

Tabalhar e intervir nos cenários de produção de cuidado nos serviços de saúde atualmente não são tarefas simples. Vivemos um momento em nosso país em que a saúde é tratada como questão de primeira importância para a população, levando gestores e profissionais de saúde a elaborar e implantar políticas públicas das mais diversas ordens, de gestão, de assistência, de educação e pesquisa, complexificando os cenários e clamando aos profissionais de saúde a atuar de forma não apenas técnica, mas também política e social.

Buscando atender a essa e a outras demandas, percebe-se que é com as diretrizes curriculares em 2001 e com a política de educação permanente na saúde em 2004 que começa a descortinar-se um forte movimento de reorientação da formação profissional em saúde e de constante formação

dos profissionais já em serviço, trazendo consigo o desafio de transformar essas práticas de cuidado no sentido de aproximálas das demandas do Sistema Único de Saúde (SUS) e concretizar os princípios doutrinários e organizativos da nova política de saúde.

Ao retomar a formação do enfermeiro, enfatiza-se que ela tem como centralidade a formação de profissionais generalistas, críticos, reflexivos, capazes de aprender a aprender e de atender às necessidades de saúde da população, considerando os princípios do SUS. É pautada no desenvolvimento de competências, sendo elas: atuar na atenção à saúde, tomada de decisões, comunicação, administração e gerenciamento, educação permanente e liderança ${ }^{(1)}$. Compreende-se que o desenvolvimento dessas competências contribui para a formação política do enfermeirolíder, que também podem ser espraiadas para a formação dos 
profissionais de enfermagem de maneira ampla.

Nesse movimento por mudanças, a Enfermagem possui papel de destaque - uma vez que se apresenta como a maior força de trabalho em saúde ${ }^{(2)}$ reunindo quase um milhão e meio de profissionais responsáveis pelo cuidado direto e integral dos pacientes em todos os níveis de atenção e ações de saúde -, sendo ela capaz e responsável por auxiliar efetivamente nas transformações.

Todavia, para que isso ocorra, é necessária uma formação que extrapole os muros das escolas e dos serviços e caminhe ao encontro de uma compreensão do País, de sua história, desenvolvimento, potencialidades; da história da profissão, de suas lutas, conquistas e desafios; uma formação que propicie o entendimento do SUS e de sua construção histórica, que proporcione uma real compreensão do que significou e representa o surgimento do SUS para a saúde e para o povo brasileiro, de modo que mobilize os profissionais de enfermagem para construí-lo cotidianamente em seus espaços. São necessárias lideranças comprometidas com o SUS, com a Enfermagem.

Nesse sentido, o Conselho Regional de Enfermagem e a Associação Brasileira de Enfermagem, entidades representativas da categoria em Santa Catarina, elaboraram uma proposta de curso de formação que objetiva despertar e aflorar essa compreensão, desenvolvendo competências para lideranças em Enfermagem com vistas à valorização profissional e à qualificação da assistência em Enfermagem e Saúde; estimular jovens profissionais a enfrentar de modo competente, criativo e sustentável, os problemas da prática, do mercado e das condições de trabalho com vistas a evitar a evasão profissional e possibilitar aos profissionais de Enfermagem a reflexão crítica sobre a realidade política e institucional do trabalho em Saúde e Enfermagem, capacitando-os para agir como multiplicadores dessa formação pedagógica.

No que concerne à liderança, competência profissional abordada como temática central neste relato de experiência, destaca-se a existência de fragilidades em seu processo de desenvolvimento durante a formação do profissional de enfermagem, sendo exemplo a ainda majoritária prioridade do aprendizado de habilidades técnicas e seu fomento voltado apenas para os últimos semestres da graduação, o que repercute em dificuldades no exercício da liderança ${ }^{(3)}$. Por esse motivo, torna-se primordial promover o ensino transversal da liderança, assim como seu fomento através da participação em organizações políticas ou demais atividades que preencham essa lacuna(4).

Frente ao exposto, o objetivo deste trabalho é relatar a necessidade e a potencialidade da formação política para o fortalecimento da liderança em Enfermagem.

\section{METODOLOGIA}

O curso de formação política para lideranças em Enfermagem O curso de formação política para lideranças em Enfermagem foi uma atividade realizada em parceria entre o Conselho Regional de Enfermagem (Seção Santa Catarina) e a Associação Brasileira de Enfermagem (Seção Santa Catarina), realizada de setembro a dezembro de 2011 na Assembleia Legislativa do estado. Com ampla divulgação nos sítios das entidades, a inscrição dos interessados foi realizada através do portal da escola do legislativo, sendo inicialmente oferecidas 60 vagas para todo o estado, as quais foram ampliadas para $80 \mathrm{em}$ virtude da demanda. Foram inscritos enfermeiros, técnicos, auxiliares de enfermagem e estudantes, dentre esses, lideranças de sindicatos da área da saúde, de entidades e do movimento estudantil vindos de 20 municípios catarinenses.

Constituiu-se de encontros semanais, temáticos, realizados às sextas-feiras, das 14 às 22 horas, com apresentação de trabalhos finais nas mais diversas temáticas, em geral relacionadas com os conteúdos abordados nos encontros.

\section{RESULTADOS E DISCUSSÃO}

Formação política na liderança em enfermagem, o ser político de Arendt e formação em perspectivas freireanas

A preocupação com uma formação profissional para além do tecnicismo é debate constante nas entidades de classe de Enfermagem. Em Santa Catarina, esse debate permaneceu por alguns anos fora da agenda de prioridades, entretanto, considerando sua relevância, e no intuito de trazê-lo de volta à cena, a gestão Participação 2008-2011 do Conselho Regional de Enfermagem de Santa Catarina já vislumbrava a realização de ações nessa direção desde o início de seu mandato.

Conforme o transcorrer da gestão e a retomada de parcerias, dentre essas com a Associação Brasileira de Enfermagem, fortalece-seaideia da realização de um curso deformação política para lideranças em Enfermagem em virtude da percebida necessidade de maior atuação da categoria nas entidades de classe, nas instituições de saúde e na gestão dos serviços.

No cenário atual, visualiza-se a necessidade da incorporação de profissionais que se destaquem nos serviços de saúde, que mobilizem seus pares, lideranças em Enfermagem que atuem politicamente para a consolidação dos avanços conquistados com o SUS e para a organização da categoria para o fortalecimento de suas próprias pautas.

Com base nas perspectivas freireanas, e considerando-se a necessária articulação da categoria e multiprofissional, far-se-á referência à liderança ancorada no diálogo, a qual representa a capacidade do líder de influenciar seus colaboradores a atuarem de maneira crítica sobre sua práxis, mediante o processo comunicacional horizontal, capaz de preservar e 
promover a autonomia, corresponsabilização e participação ativa dos atores sociais ${ }^{(4)}$.

Em conformidade com esse pensamento, salienta-se a necessidade de ser político, atuar politicamente, o que consiste na capacidade de utilizar-se de forma coerente da ação e do discurso perante o seu convívio com a sociedade, ação esta que não poderá acontecer no isolamento, porque estar isolado significa estar privado da capacidade de agir, que é começar, tomar a iniciativa, tornando o homem capaz de realizar o improvável e o inesperado. A ação consiste na única atividade política por excelência, praticada entre os homens, dispensando a mediação da matéria. Nesse contexto, o discurso atua enquanto mediador, interferindo diretamente nas relações humanas, pois é o discurso que faz do homem um ser político ${ }^{(5)}$.

Enquanto ser político, o homem deve fazer a diferença em sua inserção no mundo. Assim, destaca-se que o homem não é um ser de adaptação, pois uma educação que pretendesse adaptá-lo estaria minimizando suas possibilidades de ação. Diante disso, adaptar significa acomodar. O que não cabe neste período histórico, porque a saúde anseia por profissionais capazes de se tornar sujeitos de transformação, o que implica perceber-se como um ser relacional, que não se restringe à adaptação, mas que luta por mudanças e pela superação de condutas enraizadas ${ }^{(6)}$.

Para que esse processo de formação política ocorra, há a necessidade de construção de uma consciência política por parte dos atores envolvidos, nessa situação, dos profissionais de enfermagem. Dessa forma, compreendemos que o movimento de assunção de uma consciência política parte de um processo de socialização, formação, compreensão e organização deste entre seus pares. Foi assentado nesse entendimento que se construiu a proposta do curso de formação política para lideranças em Enfermagem.

O curso sempre apostou na construção de diálogos francos e abertos, dado o entendimento de que a utilização do diálogo na formação - por caracterizar-se como um fenômeno humano - que, independente da temática ou do espaço, não pode ser reduzido ao depósito de ideias de um sujeito no outro, por se tratar do encontro entre os homens enquanto seres pensantes, com a finalidade de problematizar situações, a fim de modificar a realidade. Sendo assim, o diálogo possui significado porque os sujeitos dialógicos não apenas conservam sua identidade, mas a defendem, crescendo um com o outro. Por esse motivo, o diálogo não nivela nem gera reducionismos, pelo contrário impulsiona o respeito entre os sujeitos dialógicos ${ }^{(7)}$.

Os temas abordados foram pensados de modo a incluir desde temáticas mais amplas, relacionadas à vida política do País, e questões do debate da saúde no Brasil e em Santa Catarina, a temáticas que diziam respeito diretamente ao exercício profissional da categoria. Temas como História e Organização Política dos Três Poderes, Competências Constitucionais dos Três Poderes, História Política de Santa Catarina, Liderança, Gestão e Controle Social em Saúde, Estado, Sociedade e Políticas Públicas, Organização, Participação e Representação Profissional, Democracia e Participação Política, Sociedade, Estado, o SUS e a Enfermagem, Ética, Política, Cidadania, Trabalho Profissional na Saúde e Processo de Trabalho em Saúde e Enfermagem fizeram parte das discussões do curso, buscando associações manifestas através do diálogo entre a vida política do País e a vida política e organizativa dos profissionais de enfermagem em cada uma das instituições e espaços onde atuam.

Independente da temática abordada, foi constante o estímulo à reflexão e ao diálogo. Considerando que se tratou de um espaço de formação de lideranças políticas, foi imprescindível a preservação do direito dos educandos de dizer a palavra e o dever do educador de escutá-los. Reporta-se a uma escuta autêntica, que representa o falar com eles e não somente falar a eles, porque esta seria uma maneira de não ouvi-los. Dessa forma, para ministrar os temas propostos foram convidados professores com experiência em cada área e com abordagem pedagógica capaz de fomentar a reflexão e o diálogo.

Além dessa postura de estímulo constante ao diálogo, no fim do curso, com a realização de um trabalho final, foi possível que os participantes apresentassem um texto, uma encenação, uma produção relacionando sua compreensão de alguma temática discutida no curso ou ainda destacando algo novo e pertencente a suas realidades cotidianas. Entendemos que esse espaço foi também de grande importância, visto que, se o educador decidir por sempre dizer a palavra, sem oportunizar a exposição do educando, estará cometendo um equívoco e reafirmando uma postura autoritária e elitista. Quando o educador negligencia o direito do educando de dizer a palavra, ou seja, a exposição de suas ideias e de seu discurso, estará negligenciando a formação de seres políticos, porque é o dizer a palavra que irá diferenciar os homens entre si ${ }^{(8)}$.

\section{CONCLUSÕES}

Entendemos que o curso foi um importante espaço que proporcionou reconhecimento e valorização das entidades de classe através da identificação e socialização dos diversos profissionais e estudantes presentes, possibilitando a proximidade entre profissional e entidades, auxiliando, dentre outras questões, na luta pelas pautas da categoria, como a redução da jornada de trabalho e o piso salarial.

Proporcionou também integração entre academia, serviços e entidades de classe através da preparação das atividades, 
dos convidados como palestrantes e da diversidade de atores presentes em constante troca de conhecimentos. Esse movimento proporciona renovação e fortalecimento, visto que aproxima os estudantes, uma nova geração, das entidades de classe e das lutas da categoria, bem como os serviços da academia e das entidades, o que certamente corrobora para com a enfermagem e para com o SUS.

De forma geral, acreditamos que a atividade cumpre seu papel ao despertar ao menos uma fagulha de interesse pelas lutas da categoria, pelo reconhecimento da necessidade constante de atualização da formação, do estudo, bem como pelo reconhecimento dos pares e fortalecimento da capacidade de mobilização, consciência e intervenção da Enfermagem nos seus diversos espaços de inserção.

É importante que a realização dessas atividades não seja uma responsabilidade apenas das entidades de classe, mas que os gestores alocados principalmente nas diretorias e coordenadorias de enfermagem dos serviços de saúde invistam na formação política de seus pares, e que não sejam atividades pontuais, mas que se configurem como parte de um processo de formação permanente, aliado ao estímulo de busca por formação individual dos profissionais.

A formação não deve restringir-se ao cenário acadêmico, visto que, na atualidade, a formação permanente dos enfermeiros é relevante, tendo em vista a necessidade de enfrentar as rápidas transformações no ambiente de trabalho e o avanço do conhecimento científico. Dessa maneira, os serviços de saúde - as entidades de classe - também têm a responsabilidade de contribuir para a formação de líderes, por serem considerados locais propícios para o aprimoramento permanente ${ }^{(1-9)}$.

No entanto, essa formação política carece de maiores investimentos por parte das instituições de ensino. Para tanto, precisa estar articulada a uma forma de ensino que estimule a reflexão e o pensar crítico, ou seja, uma educação problematizadora, na qual o processo de formação ocorra enquanto construção conjunta entre educador e educando, através da incorporação do diálogo em sua prática. Assim, o educador educa e é educado, da mesma forma que o educando ao ser educado também $\operatorname{educa}^{(7)}$.

Vislumbra-se que a formação política possua grande importância para o fortalecimento da liderança em Enfermagem. Contudo, sabe-se que não se trata de uma tarefa fácil. Estimular o pensar crítico e a reflexão, bem como a utilização da ação coerente com o discurso, ou seja, o dizer a palavra, requerem um exercício constante e a superação de modelos de ensino e de conduta, expressos na dificuldade de alguns educadores em promover um ensino baseado na problematização, focando-se ainda na transmissão do conhecimento, que minimiza o pensar crítico e a autonomia dos sujeitos, bem como na forma autoritária e verticalizada que algumas instituições de saúde organizam, não estando preparadas para receber enfermeiros, enquanto lideranças políticas, aspecto que necessita ser pensado tanto na academia como nos serviços de saúde.

\section{Referências}

1. Ministério da Educação (BR). Resolução n³, de 07 de novembro de 2001.

Diretrizes curriculares nacionais do curso de Graduação em Enfermagem. Diário Oficial da República Federativa do Brasil, Brasília, DF, 07 nov. 2001, seção 1, p.37.

2. Pereira MJB, Fortuna CN, Mishima SM, Almeida MCP, Matumoto S. A

enfermagem no Brasil no contexto da força de trabalho em saúde: perfil e

legislação. Rev Bras Enferm. 2009;62(5):771-77.

3. Amestoy SC, Cestari ME, Thofehrn MB, Milbrath VM, Trindade LL, Backes VMS.

Processo de formação de enfermeiros líderes. Rev Bras Enferm. 2010;63(6):940-45.

4. Amestoy SC. Liderança dialógica: perspectivas na formação de enfermeiros-

líderes [tese]. Florianópolis: Programa de Pós-Graduação em Enfermagem; 2012.
5. Arendt H. A condição humana. 10ª ed. Rio de Janeiro: Forense Universitária; 2007. 6. Freire P. Pedagogia da autonomia: saberes necessários à prática educativa. 33a ed. São Paulo: Paz e Terra; 1996.

7. Freire P. Pedagogia do oprimido. $47^{a}$ ed. Rio de Janeiro: Paz e Terra; 2005.

8. Freire P. Educação como prática de liberdade. $4^{\mathrm{a}}$ ed. Rio de Janeiro: Paz e Terra; 2011.

9. Ministério da Saúde (BR). Portaria n 198/GM/MS, de 13 de fevereiro de

2004. Institui a Política Nacional de Educação Permanente em Saúde como

estratégia do Sistema Único de Saúde para a formação e o desenvolvimento de trabalhadores para o setor. Diário Oficial da República Federativa do Brasil, Brasília, DF, 13 fev.2004, p.14. 